\title{
Cooperação entre Programas de Pós-Graduação em Administração no Brasil: Evidências Estruturais em Quatro Áreas Temáticas $^{(1)}$
}

\section{Scientific Cooperation among Graduate Programs in the Field of Business in Brazil: Structural Evidence in Four Thematic Areas}

Luciano Rossoni *

Doutorando em Administração de Empresas pela UFPR. Professor do Programa de Mestrado e Doutorado da Universidade Positivo, Curitiba/PR, Brasil.

Edson Ronaldo Guarido Filho Doutor em Administração de Empresas pela UFPR. Professor do Programa de Mestrado e Doutorado da Universidade Positivo, Curitiba/PR, Brasil.

* Endereço: Luciano Rossoni

Av. Prof. Pedro Viriato Parigot de Souza, 5300, Campo Cumprido, Curitiba/PR, 81280-330. E-mail: 1rossoni@gmail.com

Copyright @ 2009 RAC. Todos os direitos, inclusive de tradução, são reservados. É permitido citar parte de artigos sem autorização prévia desde que seja identificada a fonte. 


\title{
RESUMO
}

Evidências do crescimento de cooperação entre pesquisadores e programas de pós-graduação no âmbito da produção científica têm favorecido a compreensão da construção do conhecimento científico não como empreendimento individual, mas imerso em redes de relacionamentos. Tendo isto em vista, o presente artigo objetivou verificar a presença de estruturas de cooperação entre programas de pós-graduação em Administração no Brasil em quatro áreas temáticas: ciência e tecnologia; estratégia; administração pública; e estudos organizacionais. Partiu-se da premissa de que diferentes arranjos relacionais, evidenciados por meio de relações de co-autoria, indicam formas variadas de organização do campo científico com implicações no modo de produção do conhecimento. Com base em 2.874 artigos publicados entre 2000 e 2006 em eventos temáticos e EnANPADs, foram investigadas hipóteses acerca de configurações do tipo small worlds, ligações preferenciais, centro-periferia e centralidade nos relacionamentos entre programas. Os resultados corroboraram as hipóteses revelando, em todas as áreas estudadas, estratificação entre os programas, tanto no sentido de angariar colaboradores quanto em volume de artigos. Além disso, aqueles mais produtivos tendem a se relacionar mais entre si, o que reforça outro achado: a cooperação entre programas mostrou-se fortemente associada à sua produtividade.

Palavras-chave: análise de redes sociais; conhecimento científico; cooperação; ligação preferencial; redes de colaboração científica; small worlds.

\begin{abstract}
The evidence of the growth of cooperation between researchers and graduate programs has increased our understanding of the construction of scientific knowledge as embedded in social networks. This article analyzes the structures of cooperation among Brazilian business graduate programs in four areas: science and technology, strategy, public administration and organization studies. It departs from the assumption that different relational arrangements indicate various forms of organization, with consequences to the way knowledge is produced. Based on the analysis of 2874 articles published between 2000 and 2006, we investigate hypotheses concerning small worlds, preferential attachment, core-periphery and program centrality. The results point out the stratification of programs in terms of both the number of authors and published articles. Furthermore, they evidence that the most productive programs are those with more relationships, and that cooperation between programs is strongly correlated with productivity.
\end{abstract}

Key words: social network analysis; scientific knowledge; cooperation; preferential attachment; scientific collaboration networks; small worlds. 


\section{INTRODUÇÃO}

O campo da pesquisa em Administração no Brasil apresentou forte crescimento nos últimos anos. Segundo informações da Coordenação de Aperfeiçoamento de Pessoal de Nível Superior [CAPES], de 1998 até hoje, o número de programas de pós-graduação stricto sensu em Administração no país aumentou $168 \%$, passando de 22 para 59. Paralelamente, multiplicaram-se os periódicos especializados e eventos acadêmicos na área. Como conseqüência, tem-se constatado aumento acentuado da produção científica. Dados da Associação Nacional de Pós-graduação e Pesquisa em Administração [ANPAD] indicam que o número de artigos publicados no principal evento da área passou de 250 em 1998 para 972 no ano de 2007.

Nesse contexto de desenvolvimento quantitativo da área, discussões acerca da natureza e da qualidade da produção ganharam destaque, fomentando uma diversidade de meta-estudos. A freqüência desse tipo de estudo no meio acadêmico nacional indica preocupação crescente nos últimos anos do cientista da Administração em voltar-se para si mesmo, analisando criticamente a produção acadêmica, no sentido de confrontar qualidade, rigor, relevância e originalidade.

A avaliação da produção científica brasileira teve início com o trabalho desenvolvido por Machadoda-Silva, Cunha e Amboni (1990), que investigou a área de estudos organizacionais. A partir desse estudo, diversos autores promoveram análises reflexivas a respeito da produção científica em Administração no Brasil, com pesquisas orientadas para a área amplamente considerada (p. ex. Bertero, Caldas, \& Wood, 1998; Carvalho, Goulart, \& Amantino-de-Andrade, 2005; Fleury, 2003; Vergara \& Pinto, 2001) ou de modo mais específico, às diferentes disciplinas, como organizações (p. ex. Bertero \& Keinert, 1994; Hemais \& Vergara, 2000; Rodrigues \& Carrieri, 2001; Vergara \& Carvalho, 1995), estratégia (p. ex. Bertero, Vasconcelos, \& Binder, 2003; Bignetti \& Paiva, 2002; Pegino, 2005), marketing (p. ex. Froemming et al., 2000; Vieira, 2003), recursos humanos (p. ex. Caldas, Tonelli, \& Lacombe, 2002; Tonelli, Caldas, Lacombe, \& Tinoco, 2003), sistema de informação (p. ex. Hoppen \& Meirelles, 2005), contabilidade e finanças (p. ex. Camargos, Coutinho, \& Amaral, 2005), e administração da ciência e tecnologia (p. ex. Rossoni, Ferreira, \& Hocayen-DaSilva, 2006).

Apesar da diversidade de abordagens e de problemas abordados, muitos desses estudos apontam uma questão em comum: a fragmentação da área da Administração como campo científico (vide Bertero et al., 1998; Bulgacov \& Verdu, 2003; Rodrigues \& Carrieri, 2001). Na perspectiva desses autores, a fragmentação é vista como algo negativo, já que não possibilita a formação de um corpo científico que compartilhe o conhecimento gerado em seus grupos, impossibilitando o desenvolvimento de uma ciência normal (Kuhn, 1978).

O condicionamento da atividade científica por grupos de pesquisadores evidencia o caráter social da ciência. Considerada como empreendimento coletivo e não somente fruto do trabalho individual de pesquisadores, questões ligadas à cooperação acadêmica vêm ganhando destaque no entendimento de mecanismos que favorecem o desenvolvimento científico (Barabasi, 2005; Lee \& Bozeman, 2005), em que a coesão e a proximidade entre pesquisadores se revelam recursos para a construção do conhecimento. Diante disto, o campo científico vem sendo analisado como grande rede social (Acedo, Barroso, Casanueva, \& Galán, 2006; Barabasi et al., 2002; Li-Chun, Kretschmer, Hanneman, \& ZeYuan, 2006; Liu, Bollen, Nelson, \& Van de Sompel, 2005; Moody, 2004; Newman, 2001; Otte \& Rousseau, 2002; Wagner \& Leydesdorff, 2005). Destarte, avaliar seu relacionamento é consistente com a afirmação de Moody (2004) de que cientistas imersos em redes de cooperação se influenciam mutuamente, compartilhando perspectivas e condições de operacionalização de suas pesquisas, condicionando com isso o estabelecimento de conteúdos substantivos. Praticar ciência, nesse sentido, significa estar imerso em um conjunto de relações. No entanto as repercussões dessas relações não se restringem ao contexto imediato do pesquisador, alcançando instâncias mais abrangentes. 
Nessa linha de estudos, Rossoni e colegas (Machado-da-Silva \& Rossoni, 2007; Rossoni \& Guarido, 2007; Rossoni, Guarido, \& Machado-da-Silva, 2008; Rossoni, Hocayen-da-Silva, \& Ferreira, 2008a, 2008b; Rossoni \& Machado-da-Silva, 2008) e Braga, Gomes e Ruediger (2008) pesquisaram a rede de colaboração em diferentes áreas da Administração do Brasil, na tentativa de melhor compreender a estrutura do campo científico por meio de análise de redes sociais, aplicada à cooperação entre autores e instituições de ensino.

Tendo isso em vista, o presente artigo investigou os programas de pós-graduação no Brasil considerados sob a ótica de redes de co-autoria entre pesquisadores a eles vinculados, as quais foram aqui chamadas relações de cooperação ${ }^{(2)}$. A preocupação em avaliar os programas de pós-graduação em Administração justifica-se por serem o lócus dos cursos de mestrado e doutorado e, portanto, centros de produção de conhecimento. Nesse sentido, partiu-se do pressuposto de que a construção do conhecimento científico permeia as relações de cooperação entre pesquisadores da comunidade acadêmica que, tomadas de modo agregado, refletem-se nos relacionamentos entre programas de pósgraduação: na medida que produzem conjuntamente um trabalho científico, representam certo grau de afinidade intelectual, já que o conhecimento no meio científico é reflexo de contextos sociais e cognitivos dinamicamente elaborados por pesquisadores (Leydesdorff, 1998; Otte \& Rousseau, 2002).

Com base no exposto, o objetivo do presente artigo é verificar a presença de estruturas de cooperação entre programas de pós-graduação em Administração no Brasil. Para tanto foram mapeadas as relações de co-autoria em diferentes áreas temáticas: ciência e tecnologia, estratégia, administração pública e estudos organizacionais. Operacionalmente, a configuração estrutural do campo será analisada: com base na coesão e proximidade entre programas (small worlds); no tocante à capacidade de alguns programas em angariar mais colaboradores que outros (ligação preferencial); em termos da estratificação da produção, cujos programas mais produtivos tendem a se relacionar mais entre si do que os programas periféricos (centro-periferia); e, por fim, a partir da associação entre a centralidade dos programas e a quantidade produzida de artigos.

Para tratar das preocupações esboçadas até aqui, organizou-se o artigo em quatro seções, além dessa introdução. Na primeira são discutidas diferentes estruturas de relações no campo científico, considerando suas características e implicações na produção do conhecimento. Configurações do tipo small-worlds, ligações preferenciais e centro-periferia são ali tratadas. Além disso, discute-se a relação entre centralidade e produtividade. A partir desses aspectos, foram construídas hipóteses de pesquisa que orientaram este estudo. Na seção seguinte, estão descritos os procedimentos metodológicos que sustentam a parte empírica do trabalho. A análise dos resultados, por sua vez, é apresentada na terceira seção na qual, para as quatro áreas temáticas da pesquisa em Administração, a configuração das redes de relações entre programas de pós-graduação foi avaliada à luz das hipóteses de pesquisa. Por fim, conclusões decorrentes da interpretação dos dados e do quadro de referência conceitual utilizado são apresentadas na última seção deste artigo.

\section{HiPóteses ACERCA DAs Estruturas de RelaÇões no CAMPo Científico}

Em muitas áreas do conhecimento, a colaboração em pesquisas e publicações é cada vez mais comum (Li-Chun et al., 2006). Há várias evidências do crescimento desta cooperação (vide Barabasi, 2005; Moody, 2004), cujas relações entre pesquisadores não só aumentam em frequiência, mas também em número de colaboradores, possibilitando a formação de redes. Assim, a construção do conhecimento científico, que tradicionalmente era vista como trabalho individual, vem sendo avaliada como grande conjunto de relacionamentos, cuja estrutura pode ser investigada por métodos formais de análise de redes sociais. Não raramente, os estudos a esse respeito têm considerado como base analítica a cooperação entre cientistas em termos de co-autoria.

Seguindo essa perspectiva, e a exemplo de outros estudos internacionais (Acedo et al., 2006; Barabasi et al., 2002; Li-Chun et al., 2006; Liu et al., 2005; Moody, 2004; Newman, 2001; Otte \& 
Rousseau, 2002; Wagner \& Leydesdorff, 2005), o presente artigo considera que diferentes arranjos relacionais indicam formas variadas de organização do campo científico e, por consequiência, do modo de produção do conhecimento. Com base nisso, foram traçadas hipóteses acerca da existência de configurações do tipo small worlds, ligações preferenciais, centro-periferia, bem como sobre a associação entre produtividade e centralidade dos programas de pós-graduação em Administração no Brasil. Cada uma delas será alvo de explicação neste referencial.

A idéia de mundos pequenos, small worlds, remete à situação em que um indivíduo pode acessar qualquer outro a partir de seus relacionamentos. Segundo Milgram (1967), apenas seis "passos" seriam necessários para se alcançar qualquer cidadão americano dentro dos Estados Unidos. Isso significa que, apesar de as pessoas manterem contato com número limitado de indivíduos, formando círculos afetivos, de amizade ou profissionais, uma gama muito maior de pessoas é acessada indiretamente a partir dos relacionamentos cultivados por esses contatos, já que cada um deles possui vínculos com indivíduos em círculos sociais diversos. Daí a expressão mundos pequenos: embora a maioria das pessoas não esteja relacionada diretamente entre si, elas se conectam indiretamente por meio de poucos intermediários (Lazzarini, 2007). Em face disso, admite-se que todo grupo social possui certo grau de abertura, de modo que qualquer relacionamento externo a esse grupo representa um aumento exponencial de possibilidades de contatos, delineando também vias para o fluxo de informações, conhecimento e influência (Granovetter, 1973).

Em termos estruturais, tem-se, por um lado, subconjuntos coesos de atores que apresentam laços relativamente fortes, diretos, intensos e freqüentes (Wasserman \& Faust, 1994), o que lhes permite possuir normas, valores, orientações e subculturas próprias (Scott, 2000). Ademais, a coesão acomoda a base para a solidariedade, identidade e comportamento coletivo em maior intensidade entre atores de dentro do grupo do que com os de fora dele. Por outro lado, porém, os grupos não se encontram em situação de isolamento, mas conectados entre si, ainda que frouxamente. Nessa situação, ressalta-se o papel de intermediação assumido por certos atores numa rede, cujos laços por eles estabelecidos possibilitam a comunicação entre grupos distintos. O conceito de small worlds, deste modo, aproxima análises de coesão (Coleman, 1990), com a abordagem de buracos estruturais (Burt, 1992) ou laços fracos (Granovetter, 1973).

Sob a perspectiva de small worlds, o processo de desenvolvimento científico não ocorre segundo uma lógica de fragmentação, com grupos de pesquisa distintos sem interface entre si. Diferentemente, considera-se que há ligações entre eles, nos quais a informação não é redundante, mantendo-se um nível de coesão necessário para que atividades se tornem familiares entre os membros dos diferentes grupos (Uzzi \& Spiro, 2005). Dessa forma, propriedades de small worlds provêem elementos para a durabilidade das estruturas de relacionamento, bem como de práticas e valores científicos (Kogut \& Walker, 2001; Rossoni \& Machado-da-Silva, 2008), fato fundamental para entender a mútua relação entre estruturas locais e globais ${ }^{(3)}$.

Tais aspectos foram constatados nas áreas de sociologia e da física por Moody (2004) e Newman (2001), respectivamente. Os autores, que analisaram a colaboração entre pesquisadores, concluíram a respeito da presença de mundos pequenos na ciência. As redes de colaboração investigadas pelos autores não se definiram por clusters distintos e refratários, mas por grupos bem delimitados, com fronteiras permeáveis, produzindo a conexão entre diferentes especialidades, mesmo estando distantes. No Brasil, resultado semelhante foi encontrado por Rossoni e Machado-da-Silva (2008) na área de estudos organizacionais e estratégia: apesar da baixa densidade da rede como um todo, foram constatados grupos em que a conectividade entre seus membros se mostrou bastante elevada. Mais do que isso, esses grupos não estavam isolados, mas ligados a outros por meio de um pequeno número de intermediários, configurando uma grande rede do tipo small worlds.

Nesse sentido, small worlds, por levantar questões sobre o contato entre diferentes segmentos das áreas, possibilita tratar de condições de permanência, em termos estruturais, de formas de produção científica, especialmente em momentos de expansão, o que não significa ausência de transformação, homogeneidade e inovação. Assim, com base nos argumentos teóricos descritos testou-se a seguinte hipótese de pesquisa: 


\section{H1: A rede de cooperação entre programas de pós-graduação das áreas de Administração estudadas apresenta estruturas do tipo small worlds.}

Além de se apresentarem como mundos pequenos, Barabasi e Albert (1999) e Barabasi et al. (2002) chamam atenção para a tendência de grandes redes se organizarem segundo ligações preferenciais. Em redes sociais reais, isso significa que a probabilidade de um novo ator social se conectar àqueles já participantes dos relacionamentos não apresenta distribuição uniforme, ampliando-se de acordo com o número de laços que um determinado ator possui. Trata-se do que Lee e Bozeman (2005) chamaram de vantagem cumulativa: quanto mais ligações um ator possui com outros, mais central ele se posiciona na rede e, por essa razão, maiores serão suas chances de cultivar novos relacionamentos.

A idéia de ligação preferencial está diretamente ligada à de estratificação na ciência, conforme discutida no passado por Merton $(1968,1988,1996)$ em termos de citação e reconhecimento de mérito científico, ou por Lotka (1924) quanto à produtividade acadêmica. Diferentemente, porém, considera a dimensão relacional entre atores no tocante à colaboração: afirmar que o mecanismo de ligação preferencial está presente em redes de co-autoria destaca a capacidade de alguns poucos atores atrair número de colaboradores significativamente maior que a maioria dos demais. Deste modo, ligações preferenciais indicam tendência de novos relacionamentos se darem a partir daqueles já existentes, definindo a trajetória de crescimento da rede.

Assim, ao considerar os programas de pós-graduação no processo de produção do conhecimento científico, estruturas de co-autoria com ligações preferenciais tendem a concentrar relações em torno de alguns poucos atores, ao passo que a maioria dos demais, contrariamente, apresentam apenas poucos colaboradores. Complementarmente, Barabasi e Albert (1999) advertem para o fato de essa situação se acentuar, quando considerado o tempo de permanência de um ator no campo. A senioridade no campo, nesse sentido, atua como catalisadora de novas relações na medida em que pode estar associada à transferência de prestígio, acesso a recursos ou hierarquias de orientação entre professor-aluno. Atores preferenciais, por essa razão, tendem a se tornar ainda mais centrais, sendo bastante responsáveis por conectar a rede ao seu redor e atuando também como direcionadores dos desenvolvimentos teóricos a serem difundidos (Moody, 2004; Wagner \& Leydesdorff, 2005). Isso implica probabilidade de produção desigual de conhecimento.

Tendo em vista esses argumentos teóricos e o crescimento da área de Administração, com a criação e desenvolvimentos de novos programas de pós-graduação nos últimos anos, testou-se a seguinte hipótese para cada uma das áreas analisadas nesse trabalho:

H2: Os relacionamentos entre programas de pós-graduação nas áreas de Administração estudadas são condicionados por uma lógica de ligação preferencial.

$\mathrm{O}$ entendimento da comunidade científica, enquanto sistema social estratificado, possibilita lidar com distinções, em termos da produção do conhecimento (Bertero et al., 1998). Nesse sentido, as conotações de centro e periferia (Borgatti \& Everett, 1999) ${ }^{(4)}$, ou produtores principais e secundários, podem ser passíveis de aplicação na compreensão de campos científicos, em termos do papel de certos atores sociais em sua estruturação.

No presente estudo, a preocupação em avaliar centro e periferia é considerada relevante na medida em que trata da relação do conhecimento produzido no campo com a densidade das relações entre programas com maior produção nas diferentes áreas da Administração analisadas. Em consonância com Zucker e Darby (1996), a existência de atores mais centrais implica considerá-los força de difusão e de legitimação do conhecimento praticado no campo, diante do capital social que construíram, promovendo a difusão de idéias, mobilização de estruturas e geração de produção científica.

Assim, partindo-se da identificação de dois grupos, o centro e a periferia, em termos de sua produtividade no campo, o argumento para pesquisa baseia-se na diferença de densidade das relações de cooperação entre programas. Em configurações do tipo centro-periferia, atores no centro estão densamente conectados entre si, enquanto os atores da periferia apresentam maior densidade de laços 
com os atores do centro do que com seus pares periféricos. Se essa situação ocorrer, a hipótese de centro-periferia pode ser comprovada.

No caso das áreas da Administração em análise, admitindo-se o rápido crescimento por que passaram nos últimos anos, espera-se que sejam encontradas configurações do tipo centro-periferia, tal expectativa se justifica pela crença de que o relacionamento com instituições centrais possa servir como mecanismo para angariar recursos, prestígio, experiência ou legitimidade por parte dos programas com pouca tradição em pesquisa, especialmente os localizados em instituições periféricas. Assim, a maior diversificação de programas aumenta a propensão para uma estrutura de centroperiferia, de modo que a produção do conhecimento seja hierarquicamente condicionada. Diante disso adotou-se a seguinte hipótese de pesquisa para as áreas da Administração:

\section{H3: A rede de cooperação entre programas de pós-graduação das áreas de Administração estudadas apresenta configuração do tipo centro-periferia.}

Até este ponto, foram discutidas diferentes configurações estruturais orientadas para a caracterização das relações em nível da rede. Estruturas do tipo small worlds, ligação preferencial e centro-periferia fazem referência a padrões relacionais, evidenciando como a produção científica está organizada em termos de colaboração. Contudo não se referem a questões sobre atores considerados individualmente com relação à sua relevância para o campo quanto à sua produtividade, suas conexões e seu posicionamento.

Nessa linha de raciocínio, a noção de centralidade é freqüentemente utilizada: quanto mais centrais mais importantes são determinados atores em uma rede. Três são as medidas comumente utilizadas para esse tipo de avaliação: centralidade de grau (degree); centralidade de proximidade (closeness); e centralidade de intermediação (betweenness) (Hanneman \& Riddle, 2005; Scott, 2000; Wasserman \& Faust, 1994).

A centralidade de grau é definida simplesmente pelo número de laços adjacentes de um ator com relação aos outros numa rede (Wasserman \& Faust, 1994), possibilitando uma avaliação da "atividade" local dos atores. Já a centralidade de proximidade é função da proximidade ou distância de um ator em relação a todos outros numa rede. A idéia subjacente é que um autor central é aquele que possui maiores condições de interagir rapidamente com todos os outros (Hanneman \& Riddle, 2005; Scott, 2000; Wasserman \& Faust, 1994). Por fim, a centralidade de intermediação avalia a dependência de atores não adjacentes de outros que atuam como uma espécie de ponte para a efetivação da interação deles (Freeman, 1979). Nesse caso, quanto maior o grau de centralidade, maior o controle potencial de um ator sobre outros que dele dependem para executar a interação.

Partindo-se dos argumentos anteriores podem-se admitir algumas relações com indicadores de centralidade. Por exemplo, na análise de small worlds, o pressuposto de existência de ligação entre diferentes grupos admite a existência na rede de atores sociais com maior grau de centralidade de intermediação e de proximidade. Já nas estruturas com ligações preferenciais, por apresentarem maior atratividade de determinados programas de pós-graduação, o conceito de centralidade de grau se faz relevante.

Diante disso, cabe questionar a relação entre essas medidas de centralidade e produção científica. Se autores individualmente se beneficiam da colaboração para ter maior produtividade (Lee \& Bozeman, 2005), é plausível que programas de pós-graduação apresentem comportamento similar. Logo, esperase que programas mais centrais tenham maior probabilidade de serem mais produtivos que os demais, em volume de autorias em trabalhos publicados. Assim, a quarta hipótese de pesquisa testada foi:

H4: Há relação positiva e significativa entre as medidas de centralidade dos programas de pósgraduação e produção científica.

Com base no quadro referencial exposto, procurou-se verificar empiricamente as redes de colaboração interinstitucional na produção científica das quatro áreas em estudo. Como se pode pensar num primeiro momento, as diferentes configurações acima tratadas - small worlds, ligação 
preferencial e centro-periferia - não são excludentes entre si, podendo ser constatadas ao mesmo tempo numa determinada rede, sem que percam suas propriedades e implicações sobre o problema da produção científica. Com o propósito de verificar esses aspectos, orientados pelas quatro hipóteses de pesquisa, delinearam-se os procedimentos metodológicos que são apresentados na sequiência.

\section{Procedimentos MetodolóGicos}

O delineamento do presente estudo, num primeiro momento, assume caráter descritivo, na medida em que procura caracterizar, para as diferentes áreas da Administração, as estruturas de relacionamento entre programas, no sentido de verificar sua conformidade com configurações do tipo small worlds, centro-periferia e escolha preferencial. Numa segunda instância, apresenta-se explicativo, na medida em que, a partir da análise das redes de cooperação, pretende compreender se programas com maior centralidade tendem a ser mais produtivos que os demais, quanto ao volume de autorias em trabalhos publicados.

Optou-se pela utilização de pesquisa documental como estratégia de coleta, pela qual foram selecionados artigos publicados em eventos científicos nacionais. Por representarem importantes espaços de comunicação acadêmica na área, a seleção ficou restrita àqueles eventos classificados como 'A' no sistema Qualis da Capes (Coordenação de Aperfeiçoamento de Pessoal de Nível Superior).

Com base neste critério, foram selecionados 2.874 artigos publicados nas áreas de administração pública e administração da ciência e tecnologia entre os anos de 2000 e 2005, e nas áreas de estratégia em organizações e estudos organizacionais entre os anos de 2001 e 2006. Foram identificados 549 artigos na área de administração pública nos Encontros Nacionais da ANPAD, 688 artigos na área de administração da ciência e tecnologia nos EnANPADs e nos Simpósios de Gestão da Inovação Tecnológica, 765 artigos na área de estratégia nos EnANPADs e nos Encontros de Estudos em Estratégia (3Es) e 872 artigos nos EnAPADs e nos Encontros Nacionais de Estudos Organizacionais [EnEO].

A não consideração de artigos publicados em periódicos pode ser apontada como uma limitação do estudo. Entretanto, por se considerar que os eventos da ANPAD representem grande volume da produção científica nas áreas estudadas, envolvendo número bastante expressivo de pesquisadores, e que parte dos artigos publicados em periódicos são preliminarmente apresentados nesses eventos, acredita-se não se ter provocado interferência sensível na análise em razão dessa opção de delineamento. Além disso, acredita-se que, embora dados advindos de outros meios possam expressar relacionamentos adicionais, a redundância tende a ser maior do que a informação complementar gerada.

O método de pesquisa empregado foi quantitativo, apoiado na análise de redes, permitindo o uso de informações sobre o relacionamento entre unidades analíticas. Dessa forma, foi possível avaliar tanto os aspectos descritivos dos relacionamentos de co-autoria, quanto realizar procedimentos estatísticos complementares na investigação de implicações causais entre as variáveis estudadas (Scott, 2000; Wasserman \& Faust, 1994). Justifica-se o uso da co-autoria devido à confiabilidade das informações e à disponibilidade de acesso, já que outros tipos de relações entre pesquisadores dificilmente estão organizados de forma sistemática. Além disso, é considerada a manifestação mais formal de colaboração acadêmica (Acedo et al., 2006).

Os dados foram tabulados com o uso do software Microsoft Excel $^{\circledR}$, considerando as relações de coautoria entre programas em cada um dos artigos identificados. Para o caso de autores vinculados a mais de uma instituição, optou-se pelo registro da primeira delas conforme indicada na origem. Por meio desse procedimento foi possível construir a estrutura das redes entre programas, cuja análise foi 
conduzida com o apoio dos softwares UCINET 6 e PAJEK 1.19 e, para os procedimentos estatísticos, do software SPSS $13.0^{\circledR}$.

Para o estudo da primeira hipótese, procedeu-se no sentido de avaliar se as propriedades estruturais da rede de relações entre programas, em cada uma das quatro áreas em questão, atendiam às condições estabelecidas por Watts e Strogatz (1998) e Watts (1999) para sua aceitação como redes do tipo small worlds. Segundo Watts e Strogatz (1998), redes small worlds apresentam distância média entre os nós (PL) menor do que em redes aleatórias, ao mesmo tempo que o coeficiente de agrupamento (CC), por sua vez, deve ser maior. Seguindo as orientações de Newman (2001) e Moody (2004), considerou-se somente o componente principal de cada uma das áreas para a avaliação dessas condições.

Já para testar a segunda hipótese, a mais complexa delas em termos de avaliação, seguindo as orientações de Barabasi e Albert (1999), identificou-se, para cada uma das áreas independentemente, a centralidade de grau dos programas de pós-graduação, ou seja, o número de pares com os quais cada um cooperou. Posteriormente, os programas foram agrupados em tabelas de freqüência em relação ao grau de cooperação, o que possibilitou a construção de gráficos de dispersão. A partir desse ponto, três procedimentos foram realizados para o teste. O primeiro deles verificou se a distribuição de freqüência dos laços se ajustava à função potência, comparando seu coeficiente de determinação com os de ajustes exponenciais, quadráticos e logarítmicos. Diferentemente de estudos anteriores, que transformaram em logaritmos a frequiência e o grau (ver Moody, 2004; Newman, 2001; Powel, White, Koput, \& Owen-Smith, 2005; Wagner \& Leydesdorff, 2005; White, Owen-Smith, Moody, \& Powell, 2004), para a posterior verificação de ajuste linear (para detalhes dessa transformação, ver Watts, 2004), optou-se por analisar diretamente o ajuste à função potência, por tal procedimento ser mais rigoroso. Caso contrário, haveria o risco de aceitar erroneamente a hipótese de ligação preferencial, já que muitas vezes se apresenta mais bem ajustada à função exponencial, mascarando os resultados (Amaral, Scala, Barthélémy, \& Stanley, 2000, discutem outras classes do mesmo fenômeno). No segundo procedimento, seguindo Wagner e Leydesdorff (2005), exportaram-se os dados de frequiência e de grau para o software LOTKA (Rousseau \& Rousseau, 2000), para avaliar novamente o ajuste da distribuição por um método mais robusto (Teste de Kolmogorov-Smirnov) que, por sua vez, possibilitou a avaliação da significância da ligação preferencial. No terceiro e último procedimento, avaliou-se o valor do expoente da função potência, visando compreender a tendência de afiliação nas áreas, admitindo que expoentes entre - 1 e -2 indicam a existência de concentração de nós com grande número de laços ${ }^{(5)}$.

Para a terceira hipótese, utilizou-se a técnica de blockmodeling, a qual possibilita extrair relações entre categorias de programas de pós-graduação. Para tanto, primeiramente, foi identificado, para cada uma das áreas isoladamente, o número de autorias de cada programa. Por meio da análise hierárquica de clusters, baseada no método Ward, procedeu-se à identificação de dois grupos quanto ao volume de artigos publicados, os quais, depois de transformados em atributos da rede, fomentaram a análise das relações entre posições. Com as posições definidas, foi possível avaliar a densidade de relações entre elas, possibilitando verificar se há configuração do tipo centro-periferia em cada uma das quatro áreas. Além disso, avaliaram-se as tendências de laços entre posições por meio do algoritmo E-I Index, que compara os números de laços dentro e fora das partições (Hanneman \& Riddle, 2005; Krackhardt \& Stern, 1988) e possui amplitude que varia de -1 a 1 . Valores positivos mais próximos de 1 indicam maior tendência de relacionamento entre atores de partições diferentes (externos), enquanto valores negativos mais próximos a -1 revelam propensão dos programas a se relacionarem internamente à própria partição de que fazem parte.

Por fim, para a quarta hipótese delineada no estudo, avaliou-se a relação entre os indicadores de centralidade da rede: grau, proximidade e intermediação, e os de produção científica de cada área separadamente. Selecionou-se como indicador de produção o número de autorias por programa, que foi utilizada como variável dependente. Posteriormente, as variáveis foram organizadas em matriz, para que fosse possível avaliar a correlação e a multicolinearidade. Depois da identificação das variáveis significativas, foram construídos modelos explicativos a partir de regressão linear simples e múltipla. Foram aceitos como significativos os resultados com nível de confiança de $95 \%(p<0,05)$. 
Além disso, ilustrou-se graficamente a relação entre produção científica e centralidade de grau por meio de gráficos de redes desenvolvidos com o software PAJEK. 1.19.

\section{ANÁlise das ConfiguraÇões Estruturais entre Programas de PÓS-GraduAÇÃo em ADMINISTRAÇÃO}

A Figura 1 ilustra as redes de relações entre programas de pós-graduação das quatro áreas estudadas. Nela, cada nó representa um programa, cujos laços expressam relações de co-autoria. Programas que, no período estudado, não mantiveram colaboração com nenhum outro foram excluídos da figura, restando apenas os componentes ${ }^{(6)}$ com dois ou mais nós, indicados pelos tons de cinza.

Figura 1: Redes de Relações entre Programas de Pós-Graduação nas Quatro Áreas Estudadas

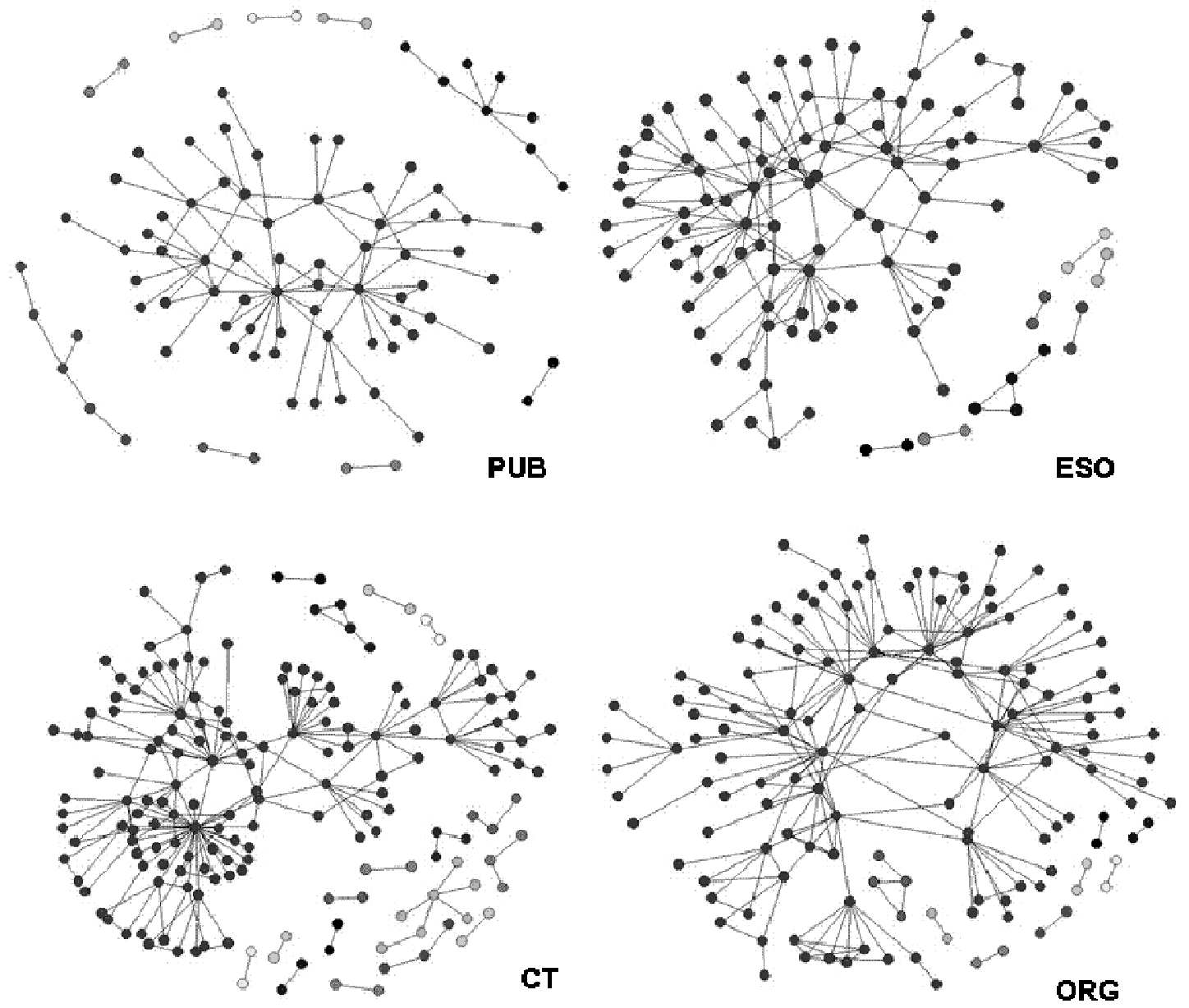

Legenda: (PUB) Adm. Pública; (CT) Adm. da Ciência e Tecnologia; (ESO) Estratégia; (ORG) Organizações.

Conforme se observa, as redes não se mostraram totalmente conectadas, apresentando vários pequenos agrupamentos em torno de um grupo de maior tamanho, chamado componente principal. Hipoteticamente, se as áreas se apresentam mais aglomeradas, formando grande componente de programas conectados entre si, maior é o potencial de troca de informações, aproveitando o canal de comunicação aberto em virtude dos relacionamentos que cultivam. Nestas circunstâncias, pode ocorrer maior similaridade de práticas de pesquisa e de definição de temáticas, o que supostamente provoca maior homogeneidade no campo. 
Entre as quatro áreas estudadas, a que apresentou menor percentual de programas agrupados no componente principal foi a de administração pública, envolvendo 53\% de um total de 120 com publicações na área. Em organizações, esse percentual alcança $72 \%$ dos 172 programas, sendo maior do que o das demais áreas (vide Tabela 1). Já para os outros componentes de tamanho reduzido, notase o inverso, estando em administração pública os maiores deles, com 7\% e 5\% do total de programas de pós-graduação.

\section{Tabela 1: Número de Programas por Componente}

\begin{tabular}{|l|c|c|c|c|c|c|c|c|}
\hline & \multicolumn{2}{|c|}{ Adm. Pública } & \multicolumn{2}{c|}{ Ciência e Tecnol. } & \multicolumn{2}{c|}{ Estratégia } & \multicolumn{2}{c|}{ Organizações } \\
\hline Número de Componentes & 10 & - & 18 & - & 8 & - & 9 & - \\
\hline Componente Principal & 63 & $53 \%$ & 133 & $57 \%$ & 100 & $67 \%$ & 124 & $72 \%$ \\
\hline $2^{\circ}$ Maior Componente & 8 & $7 \%$ & 7 & $3 \%$ & 4 & $3 \%$ & 4 & $2 \%$ \\
\hline $3^{\circ}$ Maior Componente & 6 & $5 \%$ & 4 & $2 \%$ & - & - & - & - \\
\hline Componentes Menores & 14 & $12 \%$ & 34 & $15 \%$ & 12 & $8 \%$ & 14 & $8 \%$ \\
\hline Isoladas & 29 & $24 \%$ & 54 & $23 \%$ & 33 & $22 \%$ & 30 & $17 \%$ \\
\hline Total de Programas & $\mathbf{1 2 0}$ & - & $\mathbf{2 3 2}$ & - & $\mathbf{1 4 9}$ & - & $\mathbf{1 7 2}$ & - \\
\hline
\end{tabular}

Fonte: resultados da pesquisa.

Com relação ao número de componentes em cada área, exceto de administração da ciência e tecnologia, com 18, todas as demais tiveram não mais do que 10 agrupamentos de programas, mantendo relações de co-autoria, evidenciando um grau pequeno de fragmentação. Em linhas gerais, as configurações das quatro áreas aparentaram ser bastante semelhantes, com número análogo de componentes (exceto de ciência e tecnologia), percentual de programas isolados e tamanho relativo do componente principal. Contudo, apesar das similaridades, houve diferenças, cuja exploração em maior detalhe será realizada por meio das hipóteses de pesquisa.

Todavia participar de um mesmo componente não significa que esses programas se reconheçam, muito menos que formem grupos coesos. Como indicado por Rossoni (2006), o compartilhamento de práticas de pesquisa ocorre em níveis mais específicos da interação, mais precisamente entre pesquisadores, em que a instituição tem papel relevante, mas não primordial. Os componentes indicam somente que há maior possibilidade de eles apresentarem práticas ou conhecimento compartilhados do que aqueles isolados, o que não necessariamente ocorrer de fato.

Nessa linha de raciocínio, mesmo sendo relevante para a compreensão dos padrões de cooperação do campo, o tamanho e o número de componentes exibem pouca informação sobre a dinâmica de relações entre programas de pós-graduação. Entretanto, somente a partir da identificação do componente principal é que se torna possível explorar a primeira hipótese: se as diferentes áreas da Administração investigadas apresentam uma configuração estrutural do tipo small worlds.

As estatísticas de small worlds das quatro áreas são apresentadas na Tabela 2, evidenciando que todas as áreas se enquadraram nos requisitos estruturais desse tipo de configuração: existência de grupos coesos localmente e relacionados a outros grupos por meio de poucas ligações. Como se pode observar, apesar de as redes apresentarem baixa densidade (variando de 2,1\% a 4,5\%), a distância média entre os programas foi de, no máximo, quatro passos $(3,98)$, indicando que qualquer um deles precisa de somente quatro intermediários para acessar outro na rede. Além disso, as áreas apresentaram coeficiente de agrupamento entre 0,357 e $0,589^{(7)}$, o que indica a existência de grupos mais densos localmente, ou seja, sub-conjuntos de programas que mantêm ligações com os mesmos pares, formando uma espécie de vizinhança comum.

Entre as áreas, administração da ciência e tecnologia, mesmo sendo a maior rede, apresentou coeficiente de agrupamento mais elevado $(0,589)$. Tal constatação pode ser explicada pelo fato de ser uma área de pesquisa em Administração que conta com a participação de grande quantidade de empresas e agências de fomento, como co-autoras na produção científica. Segundo Rossoni et al. 
(2008b), a integração dessas organizações ao campo depende fortemente dos vínculos que se estabelecem com programas de ensino e pesquisa que, por sua vez, atuam como intermediadores. Por consequiência, formam-se nichos mais conectados entre si, ocasionando incremento dos indicadores de agrupamento local.

A área de organizações também apresentou alto coeficiente de agrupamento $(0,516)$, porém por razões distintas. Por ser considerada madura no campo da Administração, apresenta grande diversidade temática, talvez a maior dentre as áreas investigadas (Rossoni, 2006). Tal situação estimula o desacoplamento de grupos, já que pesquisadores tendem a colaborar com pares segundo sua afinidade temática, acarretando a formação de pequenos grupos coesos e parcialmente isolados dos demais.

A hipótese de configurações do tipo small worlds se confirmou também quando analisado o indicador Q (vide Tabela 2). De acordo com Uzzi e Spiro (2005), esse indicador aponta quão estruturalmente eficientes são as condições de small worlds, devendo ser necessariamente maior do que 1. Diante disso, em conjunção com os resultados anteriores, em todas as áreas os dados corroboraram a primeira hipótese de pesquisa.

Tabela 2: Estatística de Small Worlds das Áreas Temáticas

\begin{tabular}{|l|c|c|c|c|}
\hline & PUB & CT & ESO & ORG \\
\hline Dados Observados & & & & \\
\hline Densidade do Componente Principal & $4,2 \%$ & $2,1 \%$ & $3,0 \%$ & $4,5 \%$ \\
\hline Programas no Componente Principal $(n)$ & 63 & 133 & 100 & 124 \\
\hline Média de Laços por Instituição $(k)$ & 2,57 & 2,72 & 2,96 & 2,92 \\
\hline$P L:$ Distância Média & 3,36 & 3,98 & 3,95 & 3,83 \\
\hline Distância Máxima (Diâmetro) & 7 & 9 & 9 & 7 \\
\hline$C C:$ Coeficiente de Agrupamento & 0,357 & 0,589 & 0,369 & 0,516 \\
\hline Dados aleatórios & & & & \\
\hline$C C:$ Coeficiente de Agrupamento esperado $(k / n)$ & 0,041 & 0,020 & 0,030 & 0,024 \\
\hline$P L:$ Distância Média Esperada $(\ln (n) / \ln (k))$ & 4,39 & 4,88 & 4,24 & 4,50 \\
\hline Indicadores & & & & \\
\hline$P L$ taxa $(P L$ real / $P L$ aleatório) & 0,77 & 0,81 & 0,93 & 0,85 \\
\hline$C C$ taxa $(C C$ real / $C C$ aleatório) & 8,75 & 28,78 & 12,47 & 21,92 \\
\hline$Q:$ Coeficiente $S m a l l$ World $(C C$ taxa/ $P L$ taxa) & 11,43 & 35,32 & 13,39 & 25,77 \\
\hline
\end{tabular}

Legenda: (PUB) Adm. Pública; (CT) Adm. da Ciência e Tecnologia; (ESO) Estratégia; (ORG) Organizações.

Fonte: resultados da pesquisa.

Tal constatação, diferentemente de outros meta-estudos realizados no Brasil, que afirmaram a quase inexistência de colaboração na área da Administração (Bulgacov \& Verdu, 2003; Rodrigues \& Carrieri, 2001), os resultados evidenciam empiricamente a cooperação entre programas em termos de co-autoria, ainda que não representem esforços deliberados. Evidentemente, isso não é suficiente para se ter, com segurança, elementos que impliquem o desenvolvimento da pesquisa no país; no entanto remete a duas importantes conjecturas para o campo da produção do conhecimento em Administração.

Primeiramente, apesar de as relações entre programas serem pouco densas globalmente, os altos coeficientes de agrupamento encontrados indicam a formação de vizinhanças e, a partir disso, a possibilidade de formação de capital social via coesão (Coleman, 1990). Em segundo lugar, nas quatro áreas analisadas, a distância média entre os programas é pequena, sugerindo maior dinamismo na troca de informações, de modo a fomentar o compartilhamento de significados ou o intercâmbio de conceitos e técnicas de pesquisa. Tais aspectos suscitam questões sobre o papel exercido por determinados programas na produção científica, por meio da atividade de seus pesquisadores. Alguns programas podem exercer maior atratividade em termos de estabelecimento de novas relações, 
incrementando, com isso, a propensão de serem influentes quanto ao seu poder de participar mais ativamente da comunicação do conhecimento; seriam elos chaves na conectividade entre aqueles programas ao seu redor. Diante dessa possibilidade, para as quatro áreas em análise, investigou-se a segunda hipótese de pesquisa que remete à existência de ligações preferenciais entre os programas de pós-graduação em Administração no Brasil.

Constatou-se inicialmente que, em todas as áreas, alguns programas se destacaram quanto à sua centralidade de grau, ou seja, possuíam número de colaboradores significativamente maior que a maioria dos demais (vide Tabela 3). A Universidade de São Paulo, por exemplo, quando somados os dados das quatro áreas, apresentou 80 laços, maior índice entre todos os programas. Na sequiência, aparecem a FGV-SP com 51 laços, a UFRGS, com 44, e a UFSC, com 41. Em todos esses casos, os programas de pós-graduação aparecem como os mais colaborativos em todas as áreas investigadas, colocando-os como importantes elos de articulação no âmbito do conhecimento em Administração. Outros programas, alocados em instituições como a UFMG ou UFRJ, também se destacam quanto ao número de laços, mas sua expressão tende a se concentrar em algumas das áreas especificamente.

\section{Tabela 3: Instituições/Programas com Maior Número de Laços}

\begin{tabular}{|l|c|c|c|c|c|}
\hline Instituição & Adm. Pública & Ciência e Tecnol. & Estratégia & Organizações & Total \\
\hline USP & 17 & 36 & 16 & 11 & 80 \\
\hline FGV-SP & 14 & 9 & 14 & 14 & 51 \\
\hline UFRGS & 9 & 15 & 8 & 12 & 44 \\
\hline UFSC & 6 & 9 & 9 & 17 & 41 \\
\hline UFMG & 3 & 5 & 14 & 14 & 36 \\
\hline UFRJ & 5 & 14 & 10 & 7 & 36 \\
\hline PUC-PR & 1 & 8 & 10 & 8 & 27 \\
\hline UFPR & 3 & 6 & 7 & 10 & 26 \\
\hline FGV-RJ & 5 & 2 & 6 & 12 & 25 \\
\hline UFPE & 4 & 2 & 8 & 9 & 23 \\
\hline
\end{tabular}

Fonte: resultados da pesquisa.

Com base nos dados de centralidade de grau dos programas, avaliou-se a distribuição de frequiência das relações para cada uma das quatro áreas em estudo. Na Figura 2 estão expostos os respectivos gráficos, com o volume de programas de pós-graduação representado no eixo vertical e, no eixo horizontal, a quantidade de colaboradores que possuem. Observa-se que, em todas as situações, a proporção de programas cai gradativamente, na medida em que aumenta o número de laços. Além disso, nos gráficos de menor tamanho, em que os eixos estão em notação logarítmica, observa-se que a distribuição se ajusta à reta, com concentração de pontos na parte inferior. Tais resultados evidenciam que poucos são os programas que mantêm relações de co-autoria com muitos colaboradores, ao passo que a maioria deles se limita a estabelecer conexões com número bastante reduzido de pares.

Esse tipo de distribuição exponencialmente decrescente, com cauda extensa, revela indícios de que exista tendência dos programas mais centrais, por meio de seus pesquisadores, conduzirem a entrada de outros no campo (Newman, 2001). Tal fato aponta a possibilidade de os relacionamentos de coautoria caracterizarem ligações preferenciais nas diferentes áreas da Administração. Para assegurar essa condição, investigou-se o ajuste das distribuições à função potência, conforme discutido na metodologia deste estudo. 
Figura 2: Freqüência de Programas por Número de Colaboradores

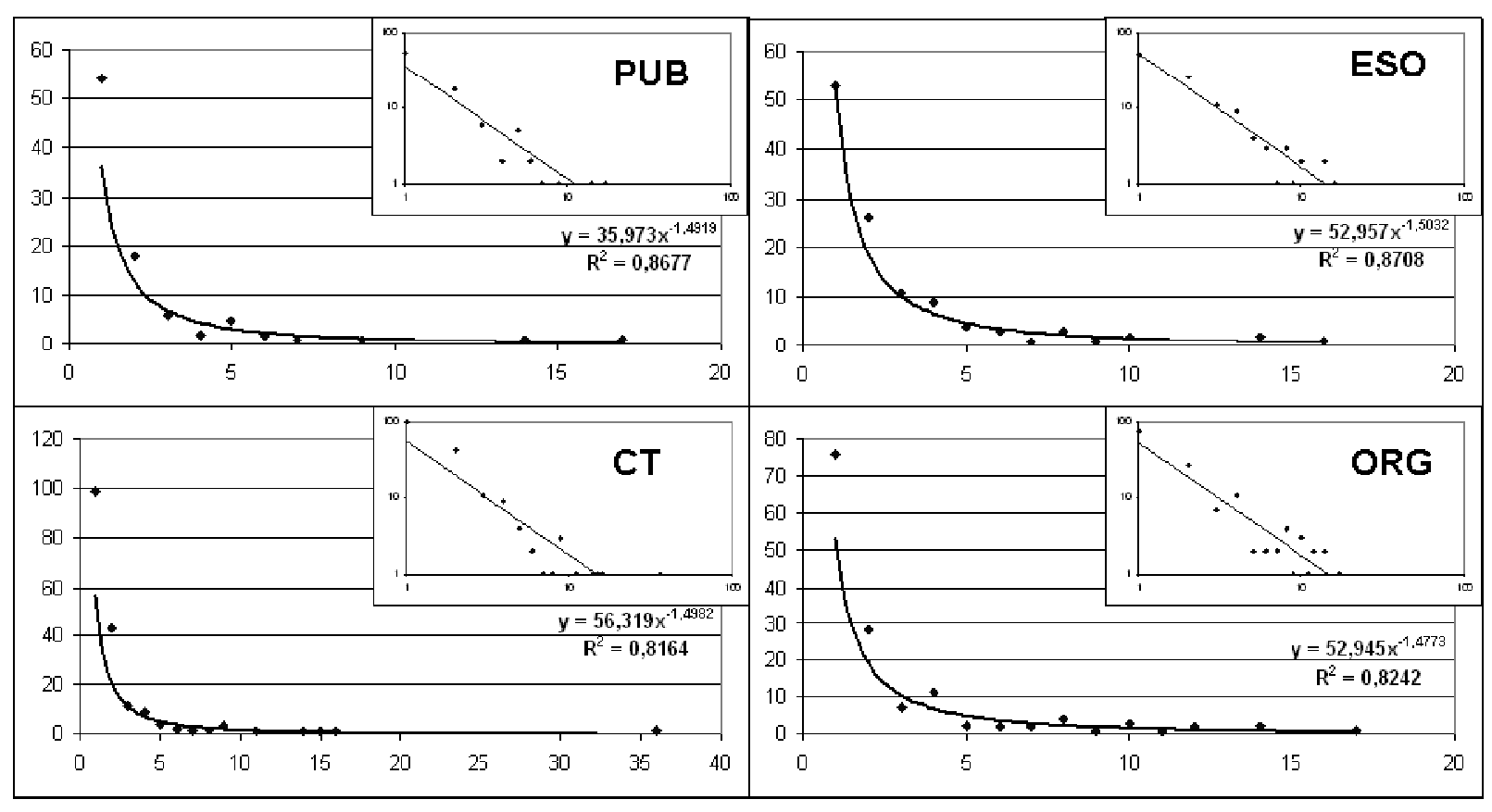

Legenda: (PUB) Adm. Pública; (CT) Adm. da Ciência e Tecnologia; (ESO) Estratégia; (ORG) Organizações.

Para todas as áreas houve ajuste significativo à função potência $(\mathrm{p}<0,001)$, com coeficiente de determinação variando de $81,6 \%$ a $87,1 \%$ (vide Tabela 4 ) e maior do que aquele calculado para outras funções alternativas. Adicionalmente, o teste de Kolmogorov-Smirnov mostrou-se também significativo para todas as áreas. Por fim, os expoentes das equações variaram entre -1,477 e - 1,503 e, portanto, dentro da faixa de valores de referência que indicam tendência de concentração de programas com destacada colaboração nas áreas. Tomados conjuntamente, esses indicadores corroboram a segunda hipótese da pesquisa e permitem afirmar que a configuração das quatro áreas analisadas expressa uma estrutura do tipo ligação preferencial, com poucos programas conduzindo a entrada da maioria dos demais no campo científico.

Tabela 4: Indicadores de Ligação Preferencial entre Programas

\begin{tabular}{|c|c|c|c|c|}
\hline & Adm. Pública & Ciência e Tecnol. & Estratégia & Organizações \\
\hline Expoente & $-1,492$ & $-1,498$ & $-1,503$ & $-1,477$ \\
\hline $\mathrm{R}^{2}$ & $86,8 \%$ & $81,6 \%$ & $87,1 \%$ & $82,4 \%$ \\
\hline Sig. & $<0,001$ & $<0,001$ & $<0,001$ & $<0,001$ \\
\hline \multicolumn{5}{|c|}{ Testes de Ajuste: } \\
\hline Valor Máx. & 0,0551 & 0,0803 & 0,1152 & 0,0593 \\
\hline $1 \%$ & $0,1709^{*}$ & $0,1222 *$ & $0,1513^{*}$ & $0,1368^{*}$ \\
\hline $5 \%$ & $0,1426^{*}$ & $0,1019 *$ & $0,1263^{*}$ & $0,1141 *$ \\
\hline $10 \%$ & $0,1279 *$ & $0,0914 *$ & 0,1133 & $0,1024 *$ \\
\hline
\end{tabular}

* Testes Goodness-of-fit de Kolmogorov-Smirnov foram significativos. Fonte: resultados da pesquisa.

Isto reflete a estratificação existente na pós-graduação no Brasil e está associado com a atuação dos pesquisadores durante sua prática acadêmica. Por haver poucos programas tradicionais na área de Administração, os quais, por muito tempo, foram os únicos a oferecerem cursos de doutorado, era esperado que recebessem maior número de alunos e pesquisadores. O papel de pesquisadores mais 
experientes e atuantes no campo, vinculados a esses programas, pode ser um dos fatores que fomentam maior conectividade com programas menores ou mais recentes. Pesquisas realizadas no Brasil e no exterior mostram que a participação desses atores no campo científico favorece configurações do tipo ligação preferencial (Guarido, 2008; Wagner \& Leydesdorff, 2005). Diante da experiência adquirida e reconhecimento acadêmico que alcançaram, tendem a acumular grande volume de colaboradores, formando redes de seguidores, nas quais exercem papel de proliferadores de conhecimento e intermediadores de novas relações (Guarido, 2008). Pesquisadores com destacada reputação ou que representem acesso a recursos, como, por exemplo, experiência ou conhecimento, tendem a ser mais acessados e, em função disso, aumentam seu prestígio, ao mesmo tempo que exercem influência sobre a produção intelectual, via articulação e compartilhamento de perspectivas (vide Merton, 1996; Moody, 2004). Por consequiência, e em razão de sua trajetória e de seus pares por diferentes instituições ao longo do tempo, podem promover a conexão estratificada entre programas de pós-graduação.

Embora mecanismos de ligação preferencial exerçam influência sobre a produção científica, isso se dá a partir da centralidade dos programas de pós-graduação, o que reflete nos conteúdos substantivos dos artigos publicados. Raciocínio diferente ocorre, quando se coloca em questão o volume produzido por esses programas. Nesse caso, o que estaria em questão é o fato da produtividade dos programas condicionar seus relacionamentos. Em função disso, investigou-se a terceira hipótese de pesquisa, que trata da avaliação da estrutura de cooperação em termos de centro-periferia.

Por meio da análise hierárquica de clusters, a partir da consideração do número de autorias dos programas, obteve-se como resultado dois agrupamentos, o que converge com o pressuposto de existência de pelo menos dois padrões de produção distintos: um mais produtivo, o centro, e outro com menor produtividade, a periferia. Na Tabela 5, estão expostos dados referentes a esses dois grupos para cada uma das áreas em estudo.

Tabela 5: Média de Autoria dos Grupos e Grau de Externalidade das Relações

\begin{tabular}{|l|c|c|c|c|c|c|}
\hline & & & \multicolumn{3}{|c|}{ Laços } & \\
\hline Método Ward & Programas & Média Autorias & Internos & Externos & Total & E-I Index \\
\hline Adm. Pública & $\mathbf{1 2 0}$ & $\mathbf{8 , 8 7}$ & $\mathbf{1 6 0}$ & $\mathbf{4 0}$ & $\mathbf{2 0 0}$ & $\mathbf{- 0 , 6 0 0} * *$ \\
\hline Periferia & 117 & $5,96^{*}$ & 156 & 20 & 176 & $-0,773$ \\
\hline Centro & 3 & $122,33^{*}$ & 4 & 20 & 24 & 0,667 \\
\hline Ciência e Tecnologia & $\mathbf{2 3 2}$ & $\mathbf{6 , 7 5}$ & $\mathbf{2 7 0}$ & $\mathbf{1 5 0}$ & $\mathbf{4 2 0}$ & $\mathbf{- 0 , 2 8 6}$ \\
\hline Periferia & 228 & $4,61^{*}$ & 264 & 75 & 339 & $-0,558$ \\
\hline Centro & 4 & $129 *$ & 6 & 75 & 81 & 0,852 \\
\hline Estratégia & $\mathbf{1 4 9}$ & $\mathbf{1 0 , 7}$ & $\mathbf{1 3 4}$ & $\mathbf{1 8 2}$ & $\mathbf{3 1 6}$ & $\mathbf{0 , 1 5 2}$ \\
\hline Periferia & 129 & $3,3 *$ & 84 & 91 & 175 & 0,040 \\
\hline Centro & 20 & $58,45^{*}$ & 50 & 91 & 141 & 0,291 \\
\hline Organizações & $\mathbf{1 7 2}$ & $\mathbf{1 0 , 4 3}$ & $\mathbf{3 3 6}$ & $\mathbf{1 4 8}$ & $\mathbf{3 8 4}$ & $\mathbf{- 0 , 2 2 9} *$ \\
\hline Periferia & 163 & $5,53^{*}$ & 220 & 74 & 294 & $-0,497$ \\
\hline Centro & 9 & $99,22^{*}$ & 16 & 74 & 90 & 0,644 \\
\hline
\end{tabular}

$*$ p-value $<0,01 * *$ p-value $<0,05$

Fonte: resultados da pesquisa.

Entre as áreas, similaridade é encontrada em administração pública e ciência e tecnologia. Em ambas, o número de programas no centro não ultrapassa $3 \%$ do total, sendo extremamente reduzido. Já em organizações e estratégia, o percentual de programas no centro alcançou, respectivamente $5,2 \%$ e $13,4 \%$ do total, com média de autorias situando-se em patamar inferior às demais áreas. De modo geral, porém, é notável, em todas as áreas, o número significativamente inferior de programas pertencentes ao centro em relação aos enquadrados como periferia ${ }^{(8)}$. O mesmo é visto quanto à média de autorias dos dois grupos, o que de imediato reflete diferença significativa quanto à quantidade de artigos produzidos. Por exemplo, em administração pública, os três programas do centro mantêm uma 
média de 122 autorias em artigos publicados na área, contra apenas 6 dos programas da periferia. Embora esses dados apontem a diferenciação entre programas centrais e periféricos, deseja-se saber a estrutura de relações entre eles, o que necessariamente requer maior aprofundamento.

A análise dos escores do E-I Index complementa esse aspecto. Os valores positivos resultantes da análise dos programas do centro apontam tendência à externalidade, ou seja, sua propensão a estabelecer relacionamentos com programas localizados na periferia (vide Tabela 5). O contrário ocorreu entre programas posicionados na periferia, cuja inclinação se deu em favor da internalidade dos laços, relacionando-se mais freqüentemente entre si. Única exceção ocorreu na área de estratégia, cujo escore da periferia foi positivo, resultado que indica tendência de relacionamento entre programas centrais e periféricos.

Mesmo relevantes, os padrões de externalidade e internalidade somente ilustram tendências de relacionamento nas áreas, pois avaliam as relações de forma absoluta, não ponderando os resultados quanto ao número de programas. Por essa razão, após a identificação dos centros e periferias, cabe discutir a densidade do relacionamento entre programas pertencentes a esses dois grupos, cujas matrizes estão expostas na Tabela 6.

Tabela 6: Matriz Densidade das Relações ente Centro e Periferia

\begin{tabular}{|l|c|c|c|c|c|c|c|c|}
\hline & \multicolumn{2}{|c|}{ Adm. Pública } & \multicolumn{2}{c|}{ Ciência e Tecnol. } & \multicolumn{2}{c|}{ Estratégia } & \multicolumn{2}{c|}{ Organizações } \\
\hline & Periferia & Centro & Periferia & Centro & Periferia & Centro & Periferia & Centro \\
\hline Periferia & 0.011 & 0.057 & 0.005 & 0.082 & 0.005 & 0.035 & 0.008 & 0.050 \\
\hline Centro & 0.057 & 0.667 & 0.082 & 0.500 & 0.035 & 0.132 & 0.050 & 0.222 \\
\hline
\end{tabular}

Fonte: resultados da pesquisa.

Como é possível notar, em todas as áreas, os dados seguem um mesmo padrão: a densidade entre os programas do centro foi significativamente maior que as demais (área sombreada na linha inferior das matrizes); já as densidades entre programas centrais e periféricos foram superiores àquelas avaliadas entre os da periferia (célula branca das matrizes). Isso significa que programas com maior produtividade se relacionam com maior freqüência, ao passo que programas periféricos pouco se relacionam entre si, mantendo laços preferencialmente com aqueles centrais.

Estruturas do tipo centro-periferia expressam uma idéia importante: a noção de grupo de referência, segundo a qual pesquisadores vinculados a programas centrais tendem a manter afinidade com outros pelos quais cultivam alguma identificação, em termos de papel, posição ou prestígio na área (McPhearson, Smith-Lovin, \& Cook, 2001). Todavia a referência também estimula a ligação entre integrantes de grupos distintos, pois expressa o reconhecimento por parte de atores periféricos da importância, prestígio, influência ou competência de atores centrais. Evidentemente, há inúmeros outros fatores que podem estar associados à estratificação na ciência, além dos mencionados, mas vale destacar que, ao contrário do que se pode imaginar, ela não se dá apenas pelo volume de produção. De qualquer modo, tais condições corroboram a terceira hipótese da pesquisa, segundo a qual as diferentes áreas apresentam configuração estrutural do tipo centro-periferia, com diferença de produtividade entre programas que influenciam o padrão de relacionamento entre eles.

Até este ponto, foi possível constatar a existência de configurações do tipo small worlds, ligação preferencial e centro-periferia nas quatro áreas estudadas. Os programas de pós-graduação se relacionam de modo a formar grupos coesos localmente, mas ligados a outros agrupamentos, os quais apresentam propensão a estarem organizados em torno de atores chaves com maior poder de atrair novas conexões para produção científica. Além disso, programas mais produtivos demonstraram manter alto grau de colaboração entre si, embora exibam abertura para a inserção de programas periféricos nas áreas em análise. Restou, por fim, questionar se o posicionamento central de determinados programas influencia a probabilidade de possuir volume de produção científica superior aos demais, o que remete à quarta hipótese de pesquisa. 
Para tanto verificou-se em cada uma das áreas temáticas investigadas a associação entre indicadores de centralidade dos programas de pós-graduação (grau, proximidade e intermediação) e a produtividade de cada um deles, considerada a partir do número de autorias. Os modelos utilizados nas análises de regressão estão dispostos na Tabela 7.

Tabela 7: Impacto da Centralidade na Produção Científica

\begin{tabular}{|l|c|c|c|c|}
\hline & \multicolumn{4}{|c|}{ Adm. Pública: n= 120 } \\
\hline & Mod. 1 & Mod. 2 & Mod. 3 & Mod. 4 \\
\hline Grau & $6,193^{*}$ & & & $3,896^{*}$ \\
\hline Closeness & & $0,786^{*}$ & & $-0,002$ \\
\hline Betweenness & & & $0,001^{*}$ & $0,001^{*}$ \\
\hline R & 0,781 & 0,537 & 0,761 & 0,798 \\
\hline R $^{2}$ & $61,10 \%$ & $28,90 \%$ & $58 \%$ & $63,60 \%$ \\
\hline Sig. & $<0,001$ & $<0,001$ & $<0,001$ & $<0,001$ \\
\hline
\end{tabular}

\begin{tabular}{|c|c|c|c|}
\hline \multicolumn{4}{|c|}{ Estratégia: $\mathbf{n}=\mathbf{1 4 9}$} \\
\hline Mod. 1 & Mod. 2 & Mod. 3 & Mod. 4 \\
\hline $5,76^{*}$ & & & $3,474^{* *}$ \\
\hline & $0,573^{*}$ & & $-0,031$ \\
\hline & & $0,076^{*}$ & $0,036^{*}$ \\
\hline 0,853 & 0,612 & 0,85 & 0,872 \\
\hline $72,70 \%$ & $37,40 \%$ & $72,30 \%$ & $76 \%$ \\
\hline$<0,001$ & $<0,001$ & $<0,001$ & $<0,001$ \\
\hline
\end{tabular}

\begin{tabular}{|l|c|c|c|c|}
\hline & \multicolumn{4}{|c|}{ Ciência e Tecnologia: $\mathbf{n}=\mathbf{2 3 2}$} \\
\hline & Mod. 1 & Mod. 2 & Mod. 3 & Mod. 4 \\
\hline Grau & $4,857^{*}$ & & & $3,247^{*}$ \\
\hline Closeness & & $0,304^{*}$ & & $-0,065^{*}$ \\
\hline Betweenness & & & $0,035^{*}$ & $0,016^{*}$ \\
\hline $\mathrm{R}$ & 0,898 & 0,46 & 0,901 & 0,93 \\
\hline $\mathrm{R}^{2}$ & $80,70 \%$ & $21,20 \%$ & $81,20 \%$ & $86,50 \%$ \\
\hline Sig. & $<0,001$ & $<0,001$ & $<0,001$ & $<0,001$ \\
\hline
\end{tabular}
Fonte: resultados da pesquisa.
Fon p 0,05

\begin{tabular}{|c|c|c|c|}
\hline \multicolumn{4}{|c|}{ Organizações: $\mathbf{n}=172$} \\
\hline Mod. 1 & Mod. 2 & Mod. 3 & Mod. 4 \\
\hline $5,803^{*}$ & & & $3,574^{*}$ \\
\hline & $0,44^{*}$ & & $-0,063$ \\
\hline & & $0,058^{*}$ & $0,030^{*}$ \\
\hline 0,837 & 0,54 & 0,846 & 0,87 \\
\hline $70,10 \%$ & $29,20 \%$ & $71,60 \%$ & $75,60 \%$ \\
\hline$<0,001$ & $<0,001$ & $<0,001$ & $<0,001$ \\
\hline
\end{tabular}

Os resultados mostram que, para todas as áreas, a centralidade de grau dos programas possui relação com sua produção científica. Como se observa no modelo 1 , o poder explicativo $\left(\mathrm{R}^{2}\right)$ variou de $61,1 \%$ em administração pública a 80,7\% em ciência e tecnologia, indicando que quanto mais colaboradores um programa possui, maior a tendência de produzir um volume mais elevado de artigos. Resultado similar foi encontrado no modelo 3, que avaliou a relação entre centralidade de intermediação e produção científica. Mais uma vez, constatou-se alto poder de explicação nas quatro áreas estudadas, chegando a ser superior que o modelo anterior na área de ciência e tecnologia. Esse resultado sugere que programas que, por meio de seus pesquisadores, exercem a aproximação de outros não diretamente ligados tendem a ser mais produtivos que os demais. Já, no modelo 2, em que foi avaliada a relação da produção científica com a centralidade de proximidade, os resultados, embora significativos em todas as áreas, evidenciaram coeficientes de explicação menores que os anteriores. Subentende-se, com isso, que o posicionamento global de um programa na rede de colaboração exerce pouca influência sobre sua produtividade, cujo efeito maior resulta das conexões mais imediatas de pesquisadores de um programa com outro.

Tal situação fica evidente quando as três medidas de centralidade foram incluídas simultaneamente como variáveis independentes no modelo 4 . À exceção de ciência e tecnologia, a centralidade de proximidade não se mostrou significativa nas outras três áreas, concentrando-se maior poder explicativo sobre indicadores locais (grau e intermediação). Isso aponta o fato de que aqueles programas que são, ao mesmo tempo, mais colaborativos e atuam como ponto de contato entre outros tendam a ser mais produtivos. De modo geral, o modelo 4 apresentou alta capacidade explicativa, com coeficientes variando de $63,6 \%$ a $86,5 \%$ entre as áreas. Esses resultados evidenciam a forte associação entre as variáveis de centralidade, especialmente as medidas locais, e produção científica, corroborando a quarta hipótese da pesquisa. 
A Figura 3 ilustra esses achados, tomando como exemplo a associação entre produção científica e centralidade de $\operatorname{grau}^{(9)}$, ambos representados como atributos dos programas de pós-graduação na rede de co-autoria. Adotou-se como parâmetro o tamanho relativo dos nós para indicar o número de autorias de cada programa. Para a centralidade de grau, utilizou-se a altura relativa dos nós na figura, de modo que programas mais colaborativos se apresentam no topo das redes.

\section{Figura 3: Relação entre Autorias e Centralidade de Grau}

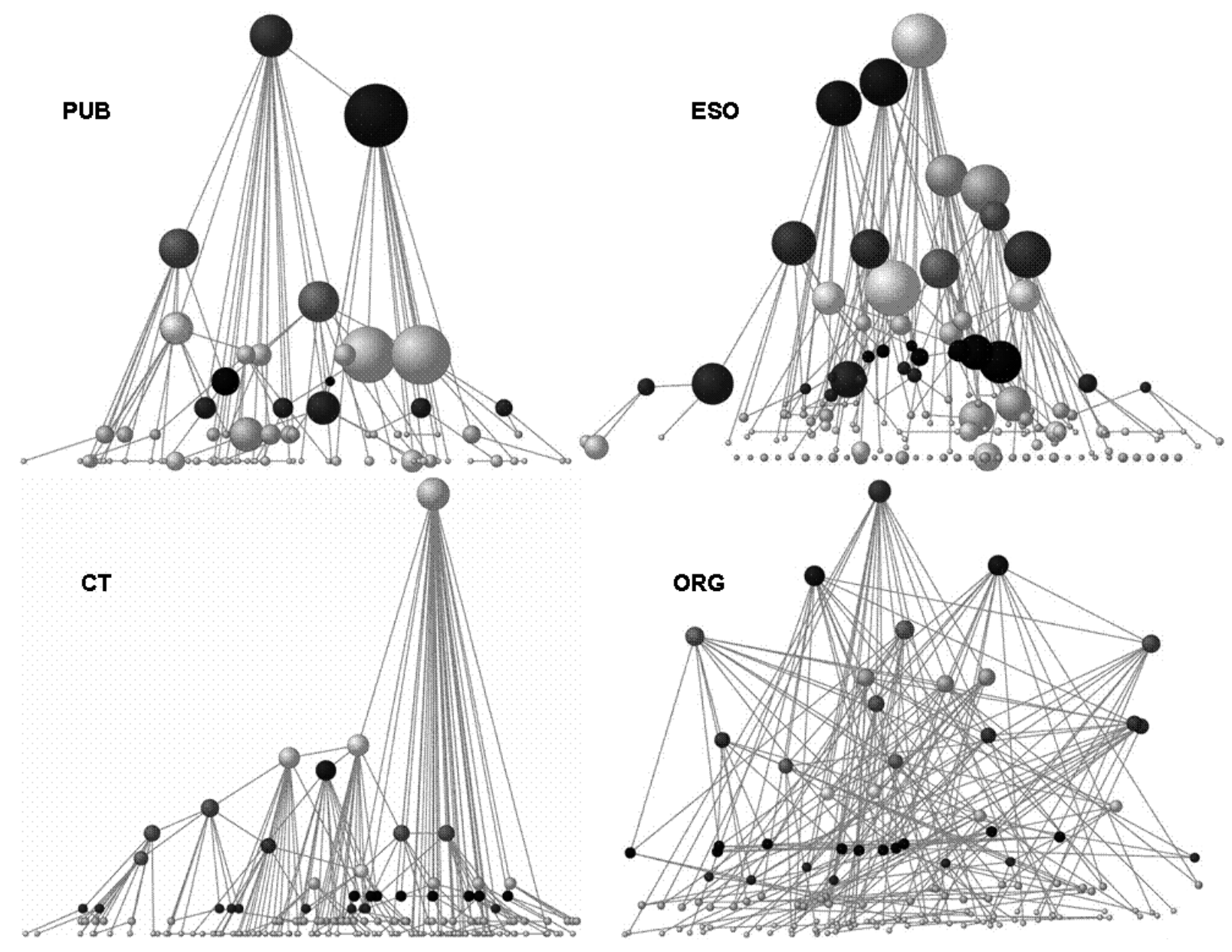

Como resultado, a topologia das quatro áreas se mostrou bastante similar, com nós maiores localizados mais acima das estruturas de relacionamento entre programas. Contudo a evidência de relação entre produção e centralidade não significa afirmar em favor de causalidade entre essas variáveis. Ressalta-se que os resultados são mais bem interpretados no sentido de sugerir a íntima associação entre elas: quanto mais central for um programa, maior será a probabilidade de apresentar numerosa produção científica.

\section{CONCLUSÕES}

No presente artigo, procurou-se verificar, a partir das relações de co-autoria, quatro hipóteses de pesquisa concernentes a estruturas de cooperação entre programas de pós-graduação em diferentes áreas da Administração no Brasil. Tal preocupação converge com aquela que nos últimos anos se tem mostrado crescente no campo da pesquisa nesta área: voltar-se para si mesmo, analisando criticamente 
sua produção acadêmica e refletindo sobre os relacionamentos sociais na construção do conhecimento científico.

Em todas as áreas estudadas, os resultados apontaram em favor da aceitação das hipóteses de pesquisa. Em cada uma delas, foi possível constatar um grande componente principal coerente com caracterização estrutural do tipo small worlds, em que agrupamentos de programas de pós-graduação se apresentavam como vizinhanças bem definidas que, por sua vez, não estavam isoladas de outros grupos, mas interligadas por meio de poucos intermediários. Tal tipo de configuração, segundo Kogut e Walker (2001), é menos suscetível à fragmentação, possibilitando, ao mesmo tempo, maior estabilidade dos relacionamentos sem solapar a capacidade criativa dos atores sociais. Isso significa que, sob esse enfoque, é possível acreditar que tais condições assegurem maior permanência das formas de conduta relativas à prática de pesquisa científica, especialmente em momentos de expansão, como aqueles pelos quais vem passando a academia brasileira em Administração. Evidentemente, não se trata de admitir uma perspectiva de coerção estrutural, segundo a qual se aceita o determinismo dos relacionamentos sociais sobre a prática da pesquisa, mas o reconhecimento de um aparato estrutural (nos termos estruturalistas) que reflete a dualidade entre agência e estrutura, conforme exposta por Giddens (1989).

Essas considerações condizem com a constatação de tendência a ligações preferenciais nas estruturas de cooperação entre programas das quatro áreas investigadas, expondo diferenças entre eles quanto à sua capacidade de estabelecer relações no campo. É interessante notar que, na combinação de estruturas small worlds com ligação preferencial, as áreas temáticas investigadas se organizam com base nos relacionamentos de certos programas de pós-graduação. Sua participação, diante disso, não se restringe apenas à troca de conhecimento no momento da produção científica por seus pesquisadores vinculados, mas pela garantia de durabilidade das suas interações. Essa última afere maior importância a esses programas, porque sua ausência acarretaria extensa ruptura do campo. Diante desse ponto, já que primordialmente os laços entre programas se pautam pelos relacionamentos entre pesquisadores, políticas em favor do fortalecimento das relações desses programas podem aumentar a resistência da rede à fragmentação.

A identificação de um claro padrão de estratificação do tipo centro-periferia revela tendência à homofilia de programas considerados centrais quanto ao volume de artigos produzidos: programas com maior produção tendem a interagir. $\mathrm{O}$ mesmo não ocorre com programas enquadrados como periféricos que tendem a se relacionar mais freqüentemente com os centrais. Levando-se em consideração o fato de programas de pós-graduação do centro, além de estarem mais próximos estruturalmente, também apresentarem maior produção, é provável que suas publicações consigam maior visibilidade do que aquelas originadas perifericamente, potenciando seu impacto sobre o conhecimento construído no campo. Reforça-se com isso a consideração de que aquilo que é considerado válido em termos acadêmicos não obedece somente a julgamentos puramente lógicos; aspectos sociais, como a noção de identificação, familiaridade e proximidade entre pesquisadores, por um lado, e prestígio, capacidades e acesso a recursos, por outro, também condicionam o que é considerado como cientificamente relevante.

A existência de forte relação entre produção científica e as medidas de centralidade, especialmente para aquelas voltadas para os relacionamentos locais, reforça a idéia de estratificação, de tal modo que os achados permitem associar condições de produtividade, ao grau de centralidade e às características dos relacionamentos estabelecidos pelos programas. Assim, como se evidencia na literatura, programas mais centrais, que aproveitam de melhor forma seus colaboradores, tendem a ser mais produtivos.

Tomados em conjunto, os resultados deste estudo permitiram identificar que o exercício científico do corpo acadêmico nas diferentes áreas estudadas apresenta similaridade, em nível estrutural, quanto à cooperação entre programas de pós-graduação. Ao contrário da fragmentação supostamente existente nas áreas da administração, verifica-se que a relações entre programas se configuram como grandes redes, cujos mecanismos foram discutidos neste trabalho de forma inovadora. 
À guisa de conclusão, ao se considerar o rápido crescimento recente das áreas investigadas, também se poderia crer que isso ocasionaria multiplicação de temas de interesse, fragmentando as linhas de pesquisa. Contudo as análises aqui destacadas demonstraram que as características dos relacionamentos entre os programas de pós-graduação acabam por estabelecer graus de coordenação nessa trajetória, pelo menos em termos estruturais. Ademais, tendo em vista que a estrutura de produção acadêmica possui um histórico que serve de referência para a produção de novos trabalhos e uma estrutura relacional e de governança entre ANPAD, instituições de ensino e pesquisa, pesquisadores e outros agentes, é provável que esse processo ocorra não caoticamente, mas de modo relativamente ordenado.

Por fim, como o estudo de redes de relações no campo científico é extremamente recente, uma gama de possibilidades para estudos futuros existe. Por exemplo, estudos multiníveis, buscando avaliar como a cooperação e a produtividade dos autores é condicionada pelas características dos programas, seria um interrante tema. Questões mais substantivas como buscar compreender se as relações entre programas e pesquisadores condicionam seus valores e práticas acadêmicas, assim como avaliar a relação entre o campo intelectual e social em termos do conteúdo dos artigos publicados podem relevar importantes descobertas para a pesquisa na área.

\title{
Artigo recebido em 24.01.2008. Aprovado em 26.08.2008.
}

\section{NOTAS}

\begin{abstract}
${ }^{1}$ O presente estudo é resultado de programa de pesquisa sobre a 'Institucionalização da Pós-Graduação em Administração no Brasil', financiado pelo PROCAD/CAPES. Versão preliminar deste artigo foi apresentada no XXXI Encontro Nacional da ANPAD de 2007, recebendo o prêmio de melhor artigo da Divisão Ensino e Pesquisa em Administração e Contabilidade. Em 2008, o trabalho recebeu o prêmio Valores do Brasil, promovido pelo Banco do Brasil, na categoria de artigo científico na área de Educação e Geração do Conhecimento. Os autores agradecem aos revisores anônimos pelos pertinentes comentários..

${ }^{2}$ Os termos cooperação e colaboração foram utilizados indistintamente ao longo do artigo, ambos indicando relações de coautoria.

${ }^{3}$ De acordo com Watts e Strogatz (1998), small worlds ocorrem quando atores em uma esparsa rede estão altamente agrupados (conformando diferentes clusters bem definidos), mas, ao mesmo tempo, estão conectados a atores fora de seus grupos por meio de um pequeno número de intermediários. Uma estrutura do tipo small worlds, nesse sentido, situa-se idealmente entre a completa regularidade e a desordem nos relacionamentos, já que, diferentemente de redes aleatórias, ao invés da distância entre os nós aumentarem conforme o tamanho da rede, eles apresentam pouca variância (Watts, 1999; Watts \& Strogatz, 1998), caracterizando uma espécie de mecanismo de "auto-ajuste" baseado na probabilidade de permanência de coordenação entre os nós, em termos estruturais, mesmo quando há grande dispersão em uma determinada rede de relacionamentos.
\end{abstract}

${ }^{4}$ A noção de centro e periferia restringe-se à constatação de um núcleo denso e coeso e uma periferia esparsa e pouco conectada (Borgatti \& Everett, 1999). Desta forma, não se trata da discussão a respeito da dependência da produção científica brasileira do contexto internacional.

${ }^{5}$ Existe uma extensa discussão no âmbito dos estudos da física sobre os critérios de avaliação de uma escolha preferencial (Moody, 2004; Wagner \& Leydesdorff, 2005; Watts, 2004). Entre os pontos de maior desacordo estão a questão do ajuste à uma função potência (Amaral et al., 2000) e o valor do expoente (Barabasi et al., 2002). Por exemplo, White et al. (2004) relacionam expoentes entre 1 e $2 \mathrm{com}$ redes em que existem vários integrantes com grande número de laços (o que empiricamente foi comprovado). Já expoentes com valores entre 2 e 3 (identificados originalmente por Barabasi \& Albert, 1999) tendem a surgir em redes mais centralizadas. No entanto, nesse último caso, Amaral et al. (2000) avaliam que em algumas dessas situações existem outros fatores que condicionam as escolhas dos laços. Para objetivos deste estudo tal discussão não é tão relevante, pois em comum há o fato de todos os modelos demonstrarem que laços em redes reais nunca são selecionados aleatoriamente, pelo contrário, sempre apresentam um mecanismo de escolha. Para uma discussão mais detalhada sobre scale-free e escolha preferencial, ver Newman, M. E. J. (2003). The structure and functions of complex networks. SIAM Review, 45(2), 167-256.

\footnotetext{
${ }^{6}$ Componentes são sub-redes em que os nós estão conectados entre si (Wasserman \& Faust, 1994).

${ }^{7} \mathrm{O}$ coeficiente de agrupamento varia de 0 a 1; quanto maior, mais aninhada localmente a rede está.

${ }^{8} \mathrm{O}$ teste $\mathrm{t}$ para médias de autorias entre instituições de centro e periferia foi significativo para todas as áreas.
} 
${ }^{9}$ Selecionou-se a centralidade de grau por ter apresentado maior poder explicativo.

\section{REFERÊNCIAS BIBLIOGRÁFICAS}

Acedo, F., Barroso, C., Casanueva, C., \& Galán, J. (2006). Co-authorship in management and organizational studies: an empirical and network analysis. Journal of Management Studies, 43(5), 957-983.

Amaral, L. A. N., Scala, A., Barthélémy, M., \& Stanley, H. E. (2000). Classes of small-world networks. Proceedings of the National of Academic Sciences, 97(21), 11149-11152.

Barabasi, A. (2005). Network theory: the emergence of the creative enterprise. Science, 308, 639-641.

Barabasi, A., \& Albert, R. (1999). Emergence of scaling in random networks. Science, 286, 509-512.

Barabasi, A., Jeong, H., Néda, Z., Ravasz, E., Schubert, A., \& Vicsek, T. (2002). Evolution of the social network of scientific collaborations. Physica A, 311(3), 590-614.

Bertero, C. O., Caldas, M. P., \& Wood, T., Jr. (1998, setembro). Produção científica em administração de empresas: provocações, insinuações e contribuições para um debate local. Anais do Encontro Nacional da Associação Nacional de Pós-Graduação e Pesquisa em Administração, Foz do Iguaçu, PR, Brasil, 22.

Bertero, C. O., \& Keinert, T. M. M. (1994). A evolução da análise organizacional no Brasil (1961-93). Revista de Administração de Empresas, 34(3), 81-90.

Bertero, C. O., Vasconcelos, F. C., \& Binder, M. P. (2003). Estratégia empresarial: a produção científica brasileira entre 1991 e 2002. Revista de Administração de Empresas, 43(4), 48-63.

Bignetti, L. P., \& Paiva, E. L. (2002). Ora (direis) ouvir estrelas: estudo das citações de autores de estratégia na produção acadêmica brasileira. Revista de Administração Contemporânea, 6(1), 105-125.

Borgatti, S. P., \& Everett, M. G. (1999). Models of core/periphery structures. Social Networks, 21(4), 375-395.

Braga, M. J. C., Gomes, L. F. A. M., \& Ruediger, M. A. (2008). Mundos pequenos, produção acadêmica e grafos de colaboração: um estudo de caso dos EnANPADs. Revista de Administração Pública, 42(1), 133-154.

Bulgacov, S., \& Verdu, F. C. (2003). Redes de pesquisadores da área de administração: um estudo exploratório. Revista de Administração Contemporânea, 5(Edição Especial), 163-182.

Burt, R. S. (1992). Structural holes: the social structure of competition. Cambridge: Harvard University Press.

Caldas, M. P., Tonelli, M. J., \& Lacombe, B. M. B. (2002, setembro). Espelho, espelho meu: metaestudo da produção científica em recursos humanos nos EnANPADs da década de 90. Anais do Encontro Nacional da Associação Nacional de Pós-Graduação e Pesquisa em Administração, Salvador, BA, Brasil, 26.

Camargos, M. A., Coutinho, E. S., \& Amaral, H. F. (2005, setembro). O perfil da área de finanças do EnANPAD: um levantamento da produção científica e de suas tendências entre 2000-2004. Anais do Encontro Nacional da Associação Nacional de Pós-Graduação e Pesquisa em Administração, Brasília, DF, Brasil, 29. 
Carvalho, C. A., Goulart, S., \& Amantino-de-Andrade, J. (2005, setembro). Internacionalização subordinada. É possível subverter as regras do jogo! Anais do Encontro Nacional da Associação Nacional de Pós-Graduação e Pesquisa em Administração, Brasília, DF, Brasil, 29.

Coleman, J. (1990). Foundations of social theory. Chicago: University of Chicago Press.

Fleury, S. (2003). Análise do perfil dos artigos publicados na Revista de Administração Pública $R A P$ - no período 1992-2002. Rio de Janeiro: EBAPE/FGV.

Freeman, L. C. (1979). Centrality in social networks: conceptual clarification. Social Networks, 1(3), 215-239.

Froemming, L. M. S., Luce, F. B., Perin, M. G., Sampaio, C. H., Beber, S. J. N., \& Trez, G. (2000). Análise da qualidade dos artigos científicos da área de marketing do Brasil: as pesquisas survey na década de 90. Revista de Administração Contemporânea, 4(3), 201-219.

Giddens, A. (1989). A constituição da sociedade. São Paulo: Martins Fontes.

Granovetter, M. S. (1973). The strength of weak ties. American Journal of Sociology, 78(6), 13611380.

Guarido, E. R., Filho (2008). A construção da teoria institucional nos estudos organizacionais no Brasil: o período 1993-2007. Tese de doutorado. Universidade Federal do Paraná, Curitiba, PR, Brasil.

Hanneman, R. A., \& Riddle, M. (2005). Introduction to social network methods. Riverside: University of Califórnia.

Hemais, B., \& Vergara, S. C. (2000, setembro). A cultura anglo-americana na produção brasileira: um estudo de intertextualidade de trabalhos em estudos organizacionais. Anais do Encontro Nacional da Associação Nacional de Pós-Graduação e Pesquisa em Administração, Florianópolis, SC, Brasil, 24.

Hoppen, N., \& Meirelles, F. S. (2005). Sistemas de informação: um panorama da pesquisa científica entre 1990 e 2003. Revista de Administração de Empresas, 45(1), 24-35.

Kogut, B., \& Walker, G. (2001). The small world of germany and the durability of national networks. American Sociological Review, 66(3), 317-335.

Krackhardt, D., \& Stern, R. (1988). Informal networks and organizational crises: an experimental simulation. Social Psychology Quarterly, 51(2), 123-140.

Kuhn, T. S. (1978). A estrutura das revoluções científicas (2a ed.). São Paulo: Perspectiva.

Lazzarini, S. G. (2007). Mudar tudo para não mudar nada: análise da dinâmica de redes de proprietários no Brasil como "mundos pequenos". RAE-Eletrônica, 6(1), art. 6. Recuperado em $30 \quad$ junho, 2008, de http://www.rae.com.br/eletronica/index.cfm?FuseAction=Artigo\&ID=3991\&Secao=FÓRU $\mathrm{M} \&$ Volume $=6 \&$ numero $=1 \& \mathrm{Ano}=2007$

Lee, S., \& Bozeman, B. (2005). The impact of research collaboration on scientific productivity. Social Studies of Science, 35(5), 673-702.

Leydesdorff, L. (1998). Theories of citation? Scientometrics, 43(1), 5-25.

Li-Chun, Y., Kretschmer, H., Hanneman, R. A., \& Ze-Yuan, L. (2006). Connection and stratification in research collaboration: an analysis of the COLLNET network. Information Processing \& Management, 42(6), 1599-1613. 
Liu, X., Bollen, J., Nelson, M. L., \& Van de Sompel, H. (2005). Co-autorship networks in the digital library research community. Information Processing \& Management, 41(6), 1462-1480.

Lotka, A. J. (1924). The frequency distribution of scientific productivity. Journal of the Washington Academy of Sciences, 16(12), 317-323.

Machado-da-Silva, C. L., Cunha, V. C., \& Amboni, N. (1990, setembro). Organizações: o estado da arte da produção acadêmica no Brasil. Anais do Encontro Nacional da Associação Nacional de Pós-Graduação e Pesquisa em Administração, Florianópolis, SC, Brasil, 14.

Machado-da-Silva, C. L., \& Rossoni, L. (2007). Persistência e mudança de temas na estruturação do campo científico da estratégia em organizações no Brasil. Revista de Administração Contemporânea, 11(4), 33-58.

McPhearson, M., Smith-Lovin, L, \& Cook, J. M. (2001). Birds of a feather: homophily in social networks. Annual Review of Sociology, 27, 415-444.

Merton, R. K. (1968). The Matthew effect in science. Science, 159(3810), 56-63.

Merton, R. K. (1988). The Matthew effect in science, II: cumulative advantage and the symbolism of intellectual property. Isis, 79(4), 606-623.

Merton, R. K. (1996). On social structure and science. Chicago: Chicago University Press.

Milgram, S. (1967). The small-world problem. Psychology Today, 1(1), 61-67.

Moody, J. (2004). The structure of a social science collaboration network: disciplinary cohesion from 1963 to 1999. American Sociological Review, 69(2), 213-238.

Newman, M. E. J. (2001). The structure of scientific collaboration networks. Proceedings of National Academic Sciences, 98(2), 404-409.

Otte, E., \& Rousseau, R. (2002). Social network analysis: a powerful strategy, also for the information sciences. Journal of Information Science, 28(6), 441-453.

Pegino, P. M. F. (2005, setembro). As bases filosóficas das publicações na área de estratégia das organizações nos encontros nacionais da ANPAD. Anais do Encontro Nacional da Associação Nacional de Pós-Graduação e Pesquisa em Administração, Brasília, DF, Brasil, 29.

Powell, W. W., White, D. R., Koput, K. W., \& Owen-Smith, J. (2005) Network dynamics and field evolution: the growth of interorganizational collaboration in the life sciences. American Journal of Sociology, 110(4), 1132-1205.

Rodrigues, S. B., \& Carrieri, A. P. (2001). A tradição anglo-saxônica nos estudos organizacionais brasileiros. Revista de Administração Contemporânea, 5(Edição Especial), 81-102.

Rossoni, L. (2006). A dinâmica de relações no campo da pesquisa em organizações e estratégia no Brasil: uma análise institucional. Dissertação de mestrado não publicada. Universidade Federal do Paraná, Curitiba, Brasil.

Rossoni, L., Ferreira, I., Jr., \& Hocayen-da-Silva, A. J. (2006, outubro). Administração de ciência e tecnologia: a produção científica brasileira entre 2000 e 2005. Anais do Simpósio de Gestão da Inovação Tecnológica, Gramado, RS, Brasil, 24.

Rossoni, L., \& Guarido, E. R., Filho (2007). Cooperação interinstitucional no campo da pesquisa em estratégia. Revista de Administração de Empresas, 47(4), 74-87.

Rossoni, L., Guarido, E. R., Filho, \& Machado-da-Silva, C. L. (2008, junho). Centralidade, produtividade e escolha preferencial: o papel da agência na construção do conhecimento 
científico em organizações e estratégia no Brasil. Anais do Encontro de Estudos Organizacionais, Belo Horizonte, MG, Brasil, 5.

Rossoni, L., \& Hocayen-da-Silva, A. J. (2008). Cooperação entre pesquisadores da área de administração da informação: evidências estruturais de fragmentação das relações no campo científico. Revista de Administração, 43(2), 138-151.

Rossoni, L., Hocayen-da-Silva, A. J., \& Ferreira, I., Jr. (2008a). Aspectos estruturais da cooperação entre pesquisadores no campo de administração pública e gestão social: análise das redes entre instituições no Brasil. Revista de Administração Pública, 42(6), 1041-1067.

Rossoni, L., Hocayen-da-Silva, A. J., \& Ferreira, I., Jr. (2008b). Estrutura de relacionamento entre instituições de pesquisa do campo de ciência e tecnologia no Brasil. Revista de Administração de Empresas, 48(4), 34-48.

Rossoni. L., \& Machado-da-Silva, C. L. (2008). Análise Institucional da Construção do Conhecimento Científico em Mundos Pequenos. Faces, 7(1), 25-43.

Rousseau, B., \& Rousseau, R. (2000). Lotka: a program to fit a power law. International Journal of Scientometrics, Informetrics and Bibliometrics, 4(1), 1-6.

Scott, J. (2000). Social network analysis: a handbook (2a ed.). London: Sage Publications.

Tonelli, M. J., Caldas, M. P., Lacombe, B. M. B., \& Tinoco, T. (2003). Produção acadêmica em recursos humanos no Brasil: 1991-2000. Revista de Administração de Empresas, 43(1), 105122.

Uzzi, B., \& Spiro, J. (2005). Collaboration and creativity: the small world problem. American Journal of Sociology, 111(2), 447-504.

Vergara, S. C., \& Carvalho, D. S., Jr. (1995, setembro). Nacionalidade dos autores referenciados na literatura brasileira sobre organizações. Anais do Encontro Nacional da Associação Nacional de Pós-Graduação e Pesquisa em Administração, João Pessoa, PB, Brasil, 19.

Vergara, S. C., \& Pinto, M. C. S. (2001). Referências teóricas em análise organizacional: um estudo das nacionalidades dos autores referenciados na literatura brasileira. Revista de Administração Contemporânea, 5(Edição Especial), 103-121.

Vieira, F. G. D. (2003). Narciso sem espelho: a publicação brasileira de marketing. Revista de Administração de Empresas, 43(1), 81-90.

Wagner, C. S., \& Leydesdorff, L. (2005). Network structure, self-organization, and the growth of international collaboration in science. Research Policy, 34(10), 1608-1618.

Wasserman, S., \& Faust, K. (1994). Social network analysis: methods and applications. Cambridge: Cambridge University Press.

Watts, D. J. (1999). Small worlds: the dynamics of networks between order and randomness. Princeton: Princeton University Press.

Watts, D. J. (2004). The "new" science of networks. Annual Review of Sociology, 30, 243-270.

Watts, D. J., \& Strogatz, S. H. (1998). Collective dynamics of "small-world" networks. Nature, 393, 440-442.

White, D. R., Owen-Smith, J., Moody, J., \& Powell, W. W. (2004). Networks, fields and organizations: micro-dynamics, scale and cohesive embeddings. Computational \& Mathematical Organization Theory, 10(1), 95-117. 
Zucker, L. G., \& Darby, M. R. (1996). Star scientists and institutional transformation: patterns of invention and innovation in the formation of the biotechnology industry. Proceedings of the National Academy of Sciences of the United States of America, 93(23), 12709-12719. 